\title{
BMJ Open Positive correlation between the expression of hEag1 and HIF-1a in breast cancers: an observational study
}

\author{
Qingxuan Lai, ${ }^{1}$ Ting Wang, ${ }^{2}$ Qingqing Guo, ${ }^{3}$ Yuxiang Zhang, ${ }^{3}$ Youxin Wang, ${ }^{3}$ \\ Li Yuan, ${ }^{1}$ Rui Ling, ${ }^{2}$ Yan He, ${ }^{3}$ Wei Wang ${ }^{3,4}$
}

To cite: Lai $Q$, Wang $T$, Guo $Q$, et al. Positive correlation between the expression of hEag1 and HIF$1 \alpha$ in breast cancers: an observational study. BMJ Open 2014;4:e005049. doi:10.1136/bmjopen-2014005049

- Prepublication history and additional material is available. To view please visit the journal (http://dx.doi.org/ 10.1136/bmjopen-2014005049).

$\mathrm{RL}$ and $\mathrm{YH}$ contributed equally to this study.

Received 13 February 2014 Revised 25 April 2014 Accepted 1 May 2014
CrossMark

For numbered affiliations see end of article.

Correspondence to Professor Yan He; yanhe118@sina.com and Dr Rui Ling; lingrui0105@163.com

\section{ABSTRACT}

Objectives: To explore the expression patterns of Eag1 (ether á go-go 1) and HIF-1 $\alpha$ (hypoxia-inducible factor $1 \alpha$ ) in a cohort of patients with breast cancer. Setting: Department of general surgery in an upper first-class hospital in Xi'an, China.

Participants: A total of 112 female Han Chinese patients with a diagnosis of invasive ductal carcinoma were included. Patients with main internal diseases, such as cardiovascular, endocrine, gastroenterological, haematological, infectious diseases, etc, were excluded.

Primary and secondary outcome measures:

Expression profiles of Eag1 and HIF- $1 \alpha$.

Results: Eag1 and HIF-1 $\alpha$ were overexpressed in the tumour tissues compared with the pair-matched control tissues, $p=0.002$ and $<0.001$, respectively. The expression of Eag1 and HIF-1 $\alpha$ was negatively correlated with tumour size, $p=0.032$ and $p=0.025$, respectively, and lymph node status $(p=0.040$, $p=0.032$, respectively). The coexpression of Eag1 and HIF- $1 \alpha$ was correlated with tumour size $(p=0.012)$, lymph node status $(\mathrm{p}=0.027)$ and tumour stage $(p=0.036)$. HIF-1 $\alpha$ has a strong correlation with hEag1 expression $(\kappa=0.731, p<0.001)$.

Conclusions: HIF-1 $\alpha$ expression has a strong correlation with $\mathrm{hEag} 1$ expression. We are the first to attempt to explore the correlation at the population level.

\section{INTRODUCTION}

Breast cancer is the leading cause of cancerrelated deaths in women, accounting for $37.4 \%$ of female deaths worldwide. ${ }^{1}$ It is predicted that breast cancer incidence will increase to $\sim 85 / 100000$ women in China by $2021 .^{2}$ Breast cancer is easier to cure in its early stages, and early diagnosis provides vital information for doctors to make proper and effective plans for each individual. There are existing biomarkers for breast cancer, such as BRCA1 and BRCA2, but their utility can be improved through combination with other new biomarkers. ${ }^{3}$ Voltage-gated potassium

\section{Strengths and limitations of this study}

- The study found positive correlation between the expression of hypoxia-inducible factor $1 \alpha$ (HIF-1 $\alpha$ ) and ether á go-go 1 (Eag1), and negative correlation with several clinical parameters, including tumour size and node status.

- The study provided highly relevant clinical support for previously published mechanistic studies and might be useful in the development of clinical and therapeutic biomarkers.

- A computerised $\mathrm{pO}_{2}$ histography system could reveal the change of the oxygen level as the tumour progresses, which might explain the negative correlation between Eag1 and/or HIF-1 $\alpha$ and clinical parameters.

channels have been shown to play a role in breast cancer, and among them, Kv1.3 has been identified as a potential diagnostic marker and therapeutic target for breast cancer. $^{4}$

Ether á go-go 1 (Eag1, Kv10.1, KCNH1) is a member of the potassium channel family. Eag1 is the first voltage-gated potassium channel that has been shown to mediate cancer progression. ${ }^{5}$ The expression of Eag1 is restricted to the brain of healthy adults, but it is also expressed in many tumour cells and tissues, such as breast cancer ${ }^{6}$ and cervical cancer. ${ }^{7}$ Moreover, Eag1 is important for tumour cell proliferation. ${ }^{5}$ The inhibition of Eag1 expression using antisense oligonucleotides or siRNA, or pharmacological inhibition with imipramine, astemizole or quinidine can reduce cell proliferation in cancer cell lines. ${ }^{6-10}$ The blockade of Eag1 by a specific monoclonal antibody or astemizole also inhibits tumour growth in vivo. ${ }^{11} 12$ In acute myeloid leukaemia (AML), channel expression was strongly correlated with increasing age, higher relapse rates and significantly shorter overall survival in the Caucasian population. ${ }^{13}$ In ovarian cancer, 
the expression of Eag1 is associated with poor survival in the Caucasian population. ${ }^{14}$ These previous epidemiological investigations are in accordance with researches at molecular and cellular levels which indicate that Eag1 favours oncogenesis and tumour progression.

The mechanism of Eagl's role in oncogenesis and cancer progression is not known yet. Interference with the cellular oxygen homoeostasis system was proposed as the potential mechanism for the oncogenic role of Eag1. ${ }^{12}$ This hypothesis was based on evidences collected at the cellular level. In NIH3T3 and Chinese hamster ovary cells, hypoxia-inducible factor $1 \alpha$ $(H I F-1 \alpha)$ levels and vascular endothelial growth factor (VEGF) secretion were elevated by Eag1 expression. ${ }^{12}$ When these Eag1-expressing cells were implanted into severe combined immune deficient (SCID) mice, tumours were induced. ${ }^{12}$ Eag1-expressing tumours showed increased angiogenesis compared with the Eag1-negative mock cells. ${ }^{12}$ Eag1 was proposed to interfere with hypoxia homeostasis by increasing basal HIF-1 activity and lowering the threshold of HIF-1 $\alpha$ activation by hypoxia. This results in VEGF secretion and thereby increased tumour vascularisation. The correlation between Eag1 and HIF-1 $\alpha$ has been proved at the cellular level. ${ }^{12}$ It would be much more supportive if this hypothesis could be proved at the population level.

As an anticancer target, Eag1 has the advantages of easy accessibility, a single molecule real-time ion channel monitor $^{15}$ and a reduced likelihood of increasing multidrug resistance as a potential regulator in tumour angiogenesis under hypoxia. ${ }^{16}$ Additionally, the channel has an extraordinarily clean background. ${ }^{15}$ Eag1 could be one of the factors which could help in making proper clinical decisions for each individual patient.

HIF-1 is the master regulator of oxygen homeostasis and is composed of HIF- $1 \alpha$ and HIF-1 $\beta$ subunits. ${ }^{17}$ HIF-1 $\alpha$ is degraded in non-hypoxic cells, whereas HIF-1 $\beta$ is constitutively expressed. ${ }^{17}$ HIF-1 activates the transcription of genes, for example, VEGF, that are important for tumour angiogenesis. ${ }^{18}$ In bladder cancer, the expression of HIF- $1 \alpha$ was closely related to tumour angiogenesis and tumour stage. ${ }^{19}$ In breast cancer, there are controversial reports. In human breast cancer cell lines, there was an inverse correlation between HIF-1 $\alpha$ induction and clonogenic survival under hypoxia. ${ }^{20}$ But HIF-1 $\alpha$ was correlated with high metastasis risk and poor overall survival in the Caucasian population. ${ }^{21}$ The complicated mechanisms of the HIF-1 $\alpha$ pathway need more evidence to elucidate the signal transduction in hypoxia-induced angiogenesis in cancer progression.

In the present study, we aimed to explore the expression patterns of Eag1 and HIF- $1 \alpha$ and the clinical significance of their expression with respect to tumour size, lymph node status, tumour stage, patient age at surgery and body mass index (BMI) at surgery. This is the first study to examine the correlation between Eag1 and HIF- $1 \alpha$ at the population level.
MATERIALS AND METHODS

\section{Patients and tissues}

The study enrolled 112 patients from the department of surgery, Xijing Hospital, Xi'an, China, from July to December 2009. The equation

$\mathrm{M}=\mathrm{m} /\left(\mathrm{p}_{0} \mathrm{q}_{1}+\mathrm{p}_{1} \mathrm{q}_{0}\right), \quad \mathrm{m}=\left\{\mathrm{Z}_{\alpha / 2}+\mathrm{Z}_{\beta} \quad(\mathrm{p}(1-\mathrm{p}))^{0.5}\right\}^{2} /(\mathrm{p}-1 / 2)^{2}$ was used to assess the size of the sample $(\mathrm{M})$. As there is no previous data on the expression of Eag1 in normal breast tissues or breast cancer tissues in the Chinese Han population, we carried out a pilot study to get data on the expression of Eag1 in breast cancer tissues and adjacent normal tissues. Eag1 was positively expressed in $93.8 \%$ $(30 / 32)$ of breast cancer tissues and $56.3 \%(18 / 32)$ of adjacent normal tissues. So we take $\alpha=0.05, \beta=0.10$. The sample size should be 22. In practice, 112 samples were analysed for the accuracy of the study. Patients were diagnosed with invasive ductal carcinoma (IDC) according to the WHO classification criteria. ${ }^{22}$ Breast cancer tissues from patients undergoing surgery were collected as case; adjacent normal tissues excised from more than $0.5 \mathrm{~cm}$ outside of the tumour served as control. Formalin-fixed, paraffin-embedded surgical specimens were examined. Lymph node status was determined through biopsy. Tumour stage was determined according to the American Joint Committee on Cancer (AJCG) Tumour size, Lymph Nodes affected, Metastases (TNM) criteria. $^{23}$

This study was approved by the ethics committee of Xijing Hospital and was conducted in accordance with the principles of the Helsinki Declaration II. Informed consent was obtained from all participants.

\section{Immunohistochemical staining}

Immunohistochemical analysis was performed as reported by Hemmerlein $e t a l^{7}$ Serial $4 \mu \mathrm{m}$ sections were prepared, and one was stained with H\&E. Slides were deparaffinised with xylene and rehydrated in graded solutions of ethanol and distilled water. Optimal staining conditions and antibody dilutions were determined using formalin-fixed and paraffin-embedded tissue samples from human cerebral cortex for Eag1. Samples from a specimen of colon adenocarcinoma with strong expression of HIF- $1 \alpha$ were used to determine the optimal staining conditions and antibody dilutions for HIF- $1 \alpha$. Negative controls were performed using non-immune serum or phosphate-buffered saline (PBS) instead of the primary antibody. The antibodies against Eag1 and HIF- $1 \alpha$ showed good specificities. Antigen retrieval was performed in a microwave oven in $10 \mathrm{mM}$ citrate buffer ( $\mathrm{pH}$ 6.0) at $700 \mathrm{~W}$ for $15 \mathrm{~min}$. Tissue sections were preincubated with normal goat serum (Zhongshanjinqiao, Beijing, China) at a 1:100 dilution in $3 \%$ bovine serum albumin/PBS. Slides were incubated overnight in a humidified chamber at $4^{\circ} \mathrm{C}$ with anti-Eag1 rabbit antiserum (Abcam, ab86204) at a 1:1200 dilution or anti-HIF- $1 \alpha$ mouse antiserum (Abcam, ab80544) at a 1:50 dilution, followed by incubation with the EnVision Peroxidase System and DAB (Zhongshanjinqiao, Beijing, China). The same protocol was used for oestrogen 
receptor $\alpha(\mathrm{ER} \alpha)$ with anti-ER $\alpha$ antiserum (Abcam, ab37438) at a 1:50 dilution and for human epidermal growth factor receptor 2 (HER2) with anti-HER2 antiserum (Abcam, ab16901) at a 1:100 dilution.

Two operators independently evaluated antigen expression, scoring it either as 'negative' (0) or 'positive' (1), as appropriate. When the two operators agreed on the same diagnosis, the conclusion was accepted; when they gave different diagnoses, a discussion was carried out to reach an agreement. Slides with less than $10 \%$ positive staining cells were considered to be negative, and those with at least $10 \%$ positive staining cells were considered positive. ${ }^{22}$

\section{Statistical analyses}

Quantitative variables were categorised into groups, for example, T1, T2 and T3 for tumour size; N0, N1, N2 and N3 for lymph node status; M0, M1 and M2 for tumour metastasis.

A rank-sum test was used to compare the differential expression of Eag1 and HIF-1 $\alpha$ between breast cancer tissues and matched adjacent normal tissues. Spearman's rank correlation was used to evaluate the correlation between the expression of Eag1 and HIF-1 $\alpha$ and clinical parameters in cancer tissues. $\mathrm{k}$ Coefficient was used to evaluate the agreement between HIF-1 $\alpha$ and Eag1 expression in cancer tissues, and the correlation between ER $\alpha$ and HER2 status with Eag1 and HIF-1 $\alpha$.

Two-sided significance tests were used throughout, and $p \leq 0.05$ was considered statistically significant. The statistical analyses were performed using SPSS V.19.0 for Windows (SPSS Inc, Chicago, Illinois, USA).

\section{RESULTS}

We examined the expression of Eag1 and HIF-1 $\alpha$ in 112 breast cancer tissue samples and adjacent normal tissue samples. The age of the patients ranged from 22 to 84 years (median 56). All 112 patients were women. There were 112 breast cancer tissue samples and 112 adjacent normal samples. Twelve patients had stage I breast cancer, 77 patients had stage II breast cancer and 23 were stage III. Patients with stage III breast cancer had a median age of 49.5, which was lower than the median age of patients with stages I and II breast cancer. Patients with lower stages had higher levels of Eag1 and HIF-1 $\alpha$ expression (table 3). Among these patients, 45 had tumours located in the left breast, and 67 were in the right breast (table 1).

Representative images of immunohistochemical analyses for Eag1 and HIF-1 $\alpha$ are shown in figure 1. Consistent with the expected intracellular localisation, Eag1 was detected at the cell membrane and in the cytoplasm, whereas HIF-1 $\alpha$ expression was observed inside the nucleus and in the cytoplasm.

Overexpression of Eag1 and HIF-1 $\alpha$ in breast cancer tissue Eag1 was detected in $85.7 \%(96 / 112)$ of the breast cancer tissue samples from the 112 patients, but it was

\begin{tabular}{lc}
$\begin{array}{l}\text { Table } 1 \text { Clinical features of the } 112 \text { patients with breast } \\
\text { cancer }\end{array}$ \\
\hline Clinical parameter & $\mathbf{N}(\%)$ \\
\hline Mean age (range) & $56.1(22-84)$ \\
Tumour size (range) & $3.5(1.0-9.7)$ \\
Tumour in left breast & $45(40.2)$ \\
Tumour stages & \\
I & $12(10.7)$ \\
II & $77(68.8)$ \\
III & $23(20.5)$ \\
Lymph node status & $81(72.3)$ \\
Positive & $31(27.7)$ \\
Negative &
\end{tabular}

expressed in only $64.3 \%(72 / 112)$ of the adjacent normal tissues. Eag1 was overexpressed in breast cancer tissue compared with matched normal tissue $(\mathrm{p}=0.002$; table 2).

HIF-1 $\alpha$ expression was found in $79.5 \%(89 / 112)$ of breast cancer cases but in $39.3 \%(44 / 112)$ of normal tissue surrounding the tumours (table 2). HIF-1 $\alpha$ was overexpressed in breast cancer tissue compared with matched normal tissue $(\mathrm{p}<0.001$; table 2$)$.

\section{Correlation between expression of Eag1 and HIF-1 $\alpha$ and clinical parameters of tumours}

Elevated Eag1 expression was significantly associated with reduced tumour size $(\mathrm{p}=0.032)$ and low lymph node status $(\mathrm{p}=0.040$; table 3$)$. No significant correlation was observed between Eag1 expression and age $(p=0.257)$, BMI $(p=0.235)$ or tumour stage $(p=0.083$; table 3).

HIF-1 $\alpha$ expression was inversely correlated with tumour size $(\mathrm{r}=-0.212, \mathrm{p}=0.025)$ and lymph node status $(\mathrm{r}=-0.207, \mathrm{p}=0.032)$. No significant correlation was observed between HIF-1 $\alpha$ expression and age $(p=0.626)$, BMI ( $p=0.063)$ or tumour stage $(\mathrm{p}=0.056$; table 3$)$.

In adjacent normal tissues, the coexpression of Eag1 and HIF-1 $\alpha$ was correlated with lymph node status $(p=0.016)$. No other significant correlation was found (see online supplementary table S1).

\section{Eag1 expression is correlated with HIF-1 $\alpha$ expression in breast cancer tissue}

The most important finding comes when Eag1 and HIF- $1 \alpha$ are considered together. As shown in table 4, there is a correlation between the expression of Eag1 and HIF- $1 \alpha(p<0.001)$ in breast cancer tissue samples. $\kappa$ Coefficient shows the agreement between HIF-1 $\alpha$ and Eag1 expression in cancer tissues. This correlation is consistent with the studies at the cellular level. Further more, the coexpression of Eag1 and HIF-1 $\alpha$ was correlated with BMI before surgery $(p=0.032)$, tumour size ( $p=0.012)$, lymph node status $(p=0.027)$ and tumour stage $(p=0.036$; table 3$)$. 

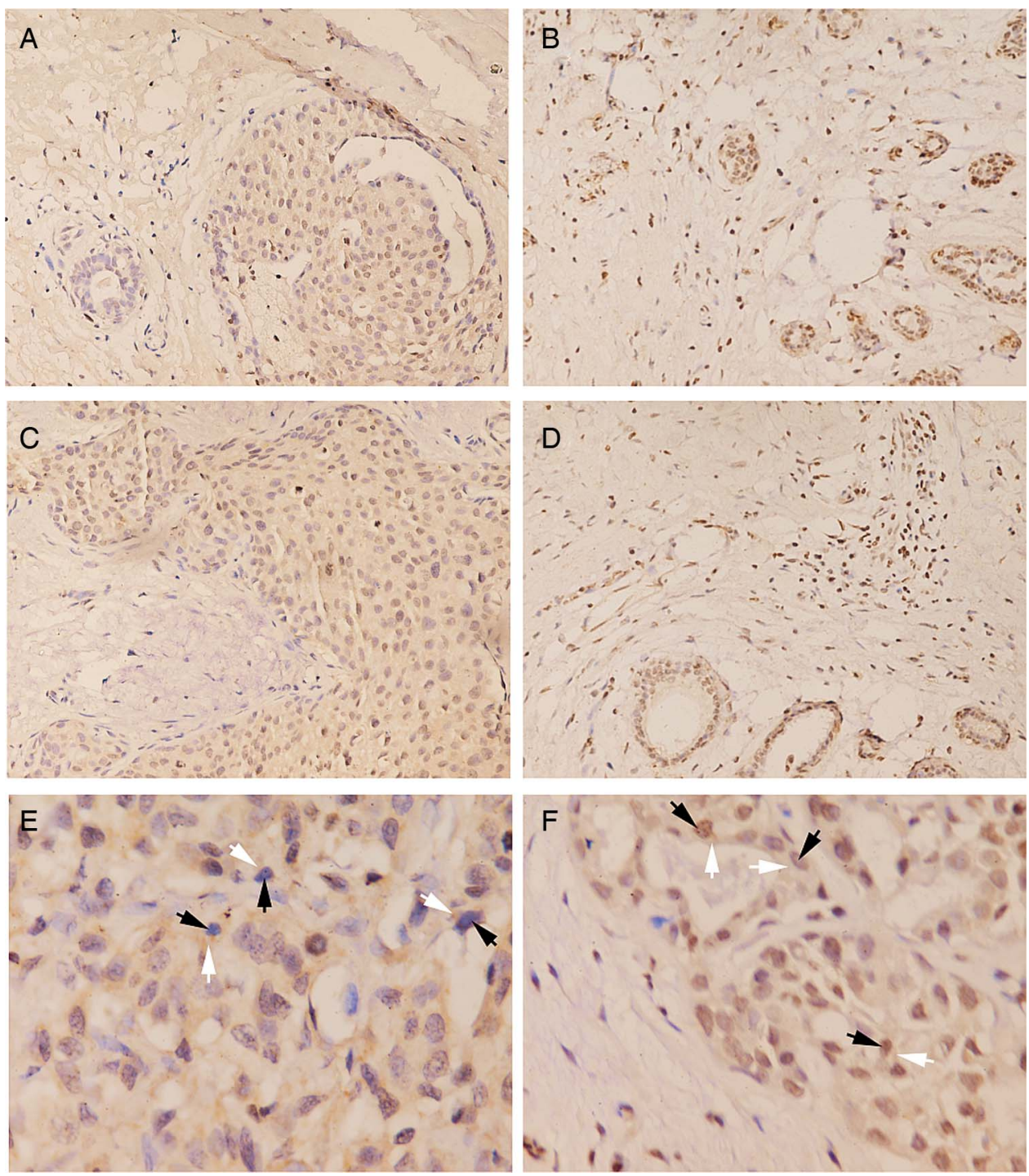

Figure 1 Representative images of breast cancer tissue staining. Ether á go-go 1 (Eag1) was not detected in adjacent normal breast tissues (A) but found at the cell membrane and in the cytoplasm in breast cancer tissues (B). The adjacent normal breast tissues show hypoxia-inducible factor $1 \alpha(\mathrm{HIF}-1 \alpha)$-negative staining (C), while HIF-1 $\alpha$ expression was found inside the nucleus in breast cancer tissues (D). Eag1 was found in the cytoplasm and the cell membrane (brown, white arrowhead) while not in the nucleus (blue, black arrowhead; E). HIF-1 $\alpha$ was found inside the nucleus (brown, black arrowhead) and the cytoplasm (brown, white arrowhead; F). (H\&E counterstain). Original magnifications: $\times 400(A-D) ; \times 1000(E$ and F).

\section{Correlation analysis of ER $\alpha$ and HER2 status with Eag1 and HIF-1a}

The expression of ER $\alpha$ and HER2 was measured in each patient. There was no significant correlation between either of the hormone receptors and Eag1 or HIF- $1 \alpha$.

Tables showing the results are available online as data supplement (see online supplementary tables S2-S5).

\section{DISCUSSION}

The expression of Eag1 and HIF-1 $\alpha$ was studied in a cohort of patients with breast cancer from a Han Chinese population. The study found positive correlation between the expression of HIF- $1 \alpha$ and Eag1, and negative correlation with several clinical parameters, including tumour size and node status.
Hemmerlein et $a l^{7}$ reported that Eag1 was overexpressed in breast cancer $85 \%$ or $82 \%$ using either a whole monoclonal antibody against EAG or a recombinant alkaline phosphatase/single chain antibody fusion, respectively). Abnormal Eag1 expression has also been reported in prostate cancer, ${ }^{7} \mathrm{AML}^{13}$ and ovarian cancer. ${ }^{14}$ The overexpression of Eag1 was validated in this study, and Eag1 was expressed in $85.7 \%$ of breast cancer tissues versus $64.3 \%$ of the adjacent normal tissues. For HIF-1 $\alpha$, the ratio was $83.9 \%$ in breast cancer tissues versus $38.4 \%$ in the normal counterparts.

Eag1 expression is positively correlated with some clinical parameters, such as tumour size in head and neck cancer $^{24}$ and lymph node metastases in colorectal cancer. ${ }^{25}$ Eag1 expression was associated with clinical parameters in different categories of cancer, including 
Table 2 The expression of human ether á go-go 1 (hEag1) and hypoxia-inducible factor $1 \alpha$ (HIF-1 $\alpha$ ) in breast cancer tissues and adjacent normal tissues $\dagger$

\begin{tabular}{lllll}
\hline Protein & Expression & $\begin{array}{l}\text { Breast } \\
\text { cancer } \\
\text { tissue }\end{array}$ & $\begin{array}{l}\text { Adjacent } \\
\text { normal } \\
\text { tissue }\end{array}$ & $\begin{array}{l}\mathbf{p} \\
\text { Value }\end{array}$ \\
\hline Eag1 & + & 87 & 72 & $0.002^{*}$ \\
& - & 25 & 40 & \\
HIF-1 $\alpha+$ & 89 & 44 & $<0.001$ \\
& - & 23 & 68 & \\
\hline
\end{tabular}

${ }^{*} p<0.05$.

†There were 112 breast cancer tissues and 112 adjacent normal tissues. Eag1 had a different distribution between (87/112) cancer tissues and (72/112) adjacent normal tissues $(\mathrm{p}=0.002)$. HIF- $1 \alpha$ was detected in 89 cancer tissues and 44 adjacent normal tissues $(p<0.001)$. A rank-sum test was used to compare the differential expression of Eag1 and HIF-1 $\alpha$ between breast cancer tissues and matched adjacent normal tissues.

epithelial origin cancers and non-epithelial origin ones. AML is a haematopoietic, non-epithelial origin cancer. In the 118 patients with AML, a subtype-dependent expression of hEag1 was found. In the most common subtypes of AML, $50 \%$ of the cases were Eag1 positive. ${ }^{13}$ Furthermore, this correlated with increasing age, higher relapse rates and significantly shorter overall survival. ${ }^{13}$ Eag1 has been correlated with poorer prognosis in AML ${ }^{13}$ ovarian, ${ }^{14}$ colorectal $^{25}$ and oesophageal cancer. ${ }^{26}$ But there is no evidence for the effect of Eag1 expression in breast cancer. We demonstrated that Eag1 was inversely correlated with tumour size and lymph node status in the 112 patients with IDC examined.

For Eag1, our research is the first attempt in breast cancer study. But this negative correlation is different from a previous study in which Eag1 expression positively correlates with clinical parameters. Yet, there is a possibility that the effect of Eag1 expression is cancertype dependent and population dependent. Eag1 channel undergoes glycosylation and other posttranslational modifications ${ }^{27}$ which are not detected by immunohistochemistry. Eag1 may play a role in the early stages of breast cancer and then degrade. Eag1 was
Table 4 Correlation/agreement between hypoxia-inducible factor $1 \alpha$ (HIF-1 $\alpha)$ and ether á go-go 1 (Eag1) expression in breast cancer tissue $\dagger$

\begin{tabular}{|c|c|c|c|c|}
\hline & 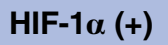 & HIF-1 $\alpha(-)$ & к & p Value \\
\hline Eag1 (+) & 86 & 6 & 0.731 & $<0.001$ \\
\hline Eag1 (-) & 3 & 16 & & \\
\hline
\end{tabular}

†Spearman's correlation was used to calculate the correlation between HIF-1 $\alpha$ and Eag1 in cancer tissues. $\kappa$ Coefficient was used to evaluate the agreement between HIF- $1 \alpha$ and Eag1 expression in cancer tissues.

proposed to interfere with hypoxia homeostasis, ${ }^{12}$ which occurs in the early stages of tumour development. ${ }^{28}$ The exploration of Eag1 function was performed in SCID mice by injection of cells into the subcutaneous space. ${ }^{5}$ This strategy does not replicate the tumoural microenvironment in which cancer cells normally develop. The microenvironment is important for Eag1 to interfere with hypoxia homeostasis. This could be an explanation for the negative correlation between Eag1 expression and breast cancer tumour stage.

We demonstrated that HIF-1 $\alpha$ expression is inversely correlated with tumour size and lymph node status. In other types of cancer, HIF- $1 \alpha$ was a marker for unfavourable prognosis, such as in early-stage invasive cervical cancer. ${ }^{29}$ It was associated with increased lymph node metastasis and worse survival in oesophageal squamouscell carcinoma ${ }^{30}$ and oropharyngeal cancer. ${ }^{31}$ But in non-small-cell lung carcinomas, ${ }^{32}$ patients with HIF-positive carcinomas had significantly longer median survival times than patients with HIF-negative carcinomas. Conflicting reports ${ }^{20}{ }^{21}$ on HIF- $1 \alpha$ and breast cancer may implicate that HIF-1 has more than one way to affect tumour progression.

It is reported that HIF- $1 \alpha$ is expressed in the early stages of breast cancer ${ }^{33}$ which has an important role in cancer progression. ${ }^{34}$ Increase of HIF-1 $\alpha$ activity by Eag1 results in VEGF secretion and thereby increased tumour vascularisation. ${ }^{12}$ There is a report about VEGF's negative correlation with breast cancer tumour grade. ${ }^{34}$ Activation of angiogenic phenotype also occurs early in tumour development and is the rate-limiting step for

Table 3 Correlation between expression of Eag1 and HIF-1 $\alpha$ and clinical parameters of tumours $†$

\begin{tabular}{|c|c|c|c|c|c|c|}
\hline \multirow[b]{2}{*}{ Variables } & \multicolumn{2}{|l|}{ Eag1 } & \multicolumn{2}{|l|}{ HIF-1 $1 \alpha$} & \multicolumn{2}{|c|}{ Coexpression } \\
\hline & $r$ & p Value & $\mathbf{r}$ & $p$ Value & $\mathbf{r}$ & p Value \\
\hline Age at operation & -0.108 & 0.257 & -0.047 & 0.626 & 0.077 & 0.417 \\
\hline BMI at operation & 0.209 & 0.235 & 0.356 & 0.063 & -0.406 & $0.032^{*}$ \\
\hline Tumour size & -0.203 & $0.032^{*}$ & -0.212 & $0.025^{*}$ & 0.236 & $0.012^{*}$ \\
\hline Lymph node status & -0.199 & $0.040^{*}$ & -0.207 & $0.032^{*}$ & 0.212 & $0.027^{*}$ \\
\hline Tumour stage & -0.164 & 0.083 & -0.181 & 0.056 & 0.199 & $0.036^{*}$ \\
\hline
\end{tabular}

${ }^{*} \mathrm{p}<0.05$, r: correlation coefficient.

†Spearman's rank correlation coefficient was used to evaluate the correlation between the expression of Eag1 and HIF-1 $\alpha$ and clinical parameters in cancer tissues. A rank-sum test was used to calculate the differences in tumour size, lymph node status and tumour stage of patients between the Eag1+ HIF-1 $\alpha+$ group and other cancer tissues.

BMI, body mass index; Eag1, ether á go-go 1; HIF-1 $\alpha$, hypoxia-inducible factor $1 \alpha$. 
tumour progression. ${ }^{35} 36$ In this situation, if we get the biopsy later, Eag1 and HIF-1 $\alpha$ will not be detected. ${ }^{37}$

The coexpression of Eag1 and HIF-1 $\alpha$ was correlated with BMI before surgery, tumour size, lymph node status and tumour stage. This result implies that an interaction between Eag1 and HIF-1 $\alpha$ might play a role in breast cancer.

More importantly, the expression of Eag1 correlates with the expression of HIF-1 $\alpha$. The correlation between Eag1 and HIF-1 $\alpha$ was observed under hypoxia. ${ }^{12}$ Hypoxia occurs in the early stages of tumour development. ${ }^{20}$ The disease-free and overall 6 -year survival rates were reported to have increased twofold in patients with cervical cancer with well-oxygenated tumours. ${ }^{14}$ Similar results occurred in head and neck cancer ${ }^{24}$ and soft tissue sarcomas. ${ }^{38}$ Eag1 was expressed in all three welloxygenated tumour types. Shorter overall and shorter recurrence-free survival was observed for patients with hypoxic tumours in which Eag1 was not detected. ${ }^{33}$

As shown in figure 1, Eag1 localises at the cell membrane and in the cytoplasm, while HIF-1 $\alpha$ localises in the cytoplasm and inside the nucleus in breast cancer tissues. Consistent with the existing reports on Eag1 and HIF- $1 \alpha,{ }^{39-42}$ the present study showed that there are subcellular location overlaps between Eag1 and HIF-1 $\alpha$, suggesting the two proteins could interact with each other in the cytoplasm. Indeed costaining could provide direct cellular evidence that Eag1 and HIF-1 $\alpha$ are coexpressed in breast cancer tissues; however, the localisations of Eag1 and HIF-1 $\alpha$ in the cytoplasm make it difficult to costain these two proteins in the same area of cancerous tissue.

\section{CONCLUSION}

In the present study, we validated that Eag1 and HIF-1 $\alpha$ were coexpressed in most breast cancer samples $(91.1 \%)$. The correlation between the expression of Eag1 and HIF-1 $\alpha$ in breast cancer tissues is in accord with the cellular research. ${ }^{12}$ The study provides highly relevant epidemiological support for previously published mechanistic studies on Eag1 and might be useful in the development of clinical and therapeutic biomarkers.

\section{Author affiliations \\ ${ }^{1}$ College of Life Science, University of Chinese Academy of Sciences, Beijing, People's Republic of China \\ ${ }^{2}$ Department of General Surgery, Xijing Hospital, Xi'an, People's Republic of China \\ ${ }^{3}$ Beijing Municipal Key Laboratory of Clinical Epidemiology, School of Public Health, Capital Medical University, Beijing, People's Republic of China ${ }^{4}$ School of Medical Sciences, Edith Cowan University, Perth, Australia}

Contributors $\mathrm{YH}, \mathrm{RL}$ and $\mathrm{WW}$ designed the study. QL, TW, QG and $\mathrm{YZ}$ performed the study. QL, YW and LY analysed the data. QL, YH and YW wrote the manuscript. $\mathrm{YH}, \mathrm{RL}$ and $\mathrm{WW}$ revised the manuscript.

Funding This study was supported by research grants from Beijing Natural Science Foundation (7132027) to YH. The study was also supported by the National Natural Science Foundation of China $(7132027,31070727$ and 81273170), National 12th Five-Year Major Projects of China (2012BAI37B03)
Australia-China Sciences Research Fund (ACSRF06444) and the Funding Project for Academic Human Resources Development in Institutions of Higher Learning under the Jurisdiction of Beijing Municipality (PHR201008393) to WW. WW was supported by the Importation and Development of High-Calibre Talents Project of Beijing Municipal Institutions.

Competing interests None.

Ethics approval The ethics committee of Xijing Hospital.

Provenance and peer review Not commissioned; externally peer reviewed.

Data sharing statement No additional data are available.

Open Access This is an Open Access article distributed in accordance with the Creative Commons Attribution Non Commercial (CC BY-NC 3.0) license, which permits others to distribute, remix, adapt, build upon this work noncommercially, and license their derivative works on different terms, provided the original work is properly cited and the use is non-commercial. See: http:// creativecommons.org/licenses/by-nc/3.0/

\section{REFERENCES}

1. Kamangar F, Dores GM, Anderson WF. Patterns of cancer incidence, mortality, and prevalence across five continents: defining priorities to reduce cancer disparities in different geographic regions of the world. J Clin Oncol 2006;24:2137-50.

2. Ziegler RG, Anderson WF, Gail MH. Increasing breast cancer incidence in China: the numbers add up. J Natl Cancer Inst 2008;100:1339-41.

3. Dowsett M, Dunbier AK. Emerging biomarkers and new understanding of traditional markers in personalized therapy for breast cancer. Clin Cancer Res 2008;14:8019-26.

4. Jang $\mathrm{SH}$, Kang KS, Ryu PD, et al. Kv1. 3 voltage-gated K (+) channel subunit as a potential diagnostic marker and therapeutic target for breast cancer. BMB Rep 2009;42:535-9.

5. Pardo LA, del Camino $D$, Sánchez $A$, et al. Oncogenic potential of EAG K+ channels. EMBO J 1999;18:5540-7.

6. Ouadid-Ahidouch $\mathrm{H}$, Le Bourhis X, Roudbaraki M, et al. Changes in the $\mathrm{K}+$ current-density of MCF-7 cells during progression through the cell cycle: possible involvement of a h-ether. a-gogo $\mathrm{K}+$ channel. Receptors Channels 2000;7:345-56.

7. Hemmerlein B, Weseloh RM, de Queiroz FM, et al. Overexpression of Eag1 potassium channels in clinical tumours. Mol Cancer 2006;5:41.

8. Niemeyer BA, Mery L, Zawar C, et al. Ion channels in health and disease: 83rd Boehringer Ingelheim Fonds International Titisee Conference. EMBO Rep 2001;2:568.

9. Gavrilova-Ruch O, Schönherr K, Gessner G, et al. Effects of imipramine on ion channels and proliferation of IGR1 melanoma cells. J Membr Biol 2002;188:137-49.

10. Weber C, de Queiroz FM, Downie BR, et al. Silencing the activity and proliferative properties of the human Eag1 potassium channel by RNA interference. J Biol Chem 2006;281:13030-7.

11. Gómez-Varela D, Zwick-Wallasch $E$, Knötgen $\mathrm{H}$, et al. Monoclonal antibody blockade of the human Eag1 potassium channel function exerts antitumor activity. Cancer Res 2007;67:7343-9.

12. Downie BR, Sánchez A, Knötgen $\mathrm{H}$, et al. Eag1 expression interferes with hypoxia homeostasis and induces angiogenesis in tumors. J Biol Chem 2008;283:36234-40.

13. Agarwal JR, Griesinger F, Stühmer W, et al. The potassium channe Ether à go-go is a novel prognostic factor with functional relevance in acute myeloid leukemia. Mol Cancer 2010;9:2-16.

14. Asher V, Khan R, Warren A, et al. The Eag potassium channel as a new prognostic marker in ovarian cancer. Diagn Pathol 2010;5:78.

15. Pardo LA, Stühmer W. Eag1: an emerging oncological target. Cancer Res 2008;68:1611-13.

16. Kerbel R, Folkman J. Clinical translation of angiogenesis inhibitors Nat Rev Cancer 2002;2:727-39.

17. Wang GL, Jiang B-H, Rue EA, et al. Hypoxia-inducible factor 1 is a basic-helix-loop-helix-PAS heterodimer regulated by cellular $\mathrm{O} 2$ tension. Proc Natl Acad Sci USA 1995;92:5510-14.

18. Koong AC, Denko NC, Hudson KM, et al. Candidate genes for the hypoxic tumor phenotype. Cancer Res 2000;60:883-7.

19. Theodoropoulos VE, Lazaris AC, Sofras F, et al. Hypoxia-inducible factor $1 \alpha$ expression correlates with angiogenesis and unfavorable prognosis in bladder cancer. Eur Urol 2004;46:200-8.

20. Blancher C, Moore JW, Talks KL, et al. Relationship of hypoxia-inducible factor (HIF)-1 $\alpha$ and HIF-2 $\alpha$ expression to vascular 
endothelial growth factor induction and hypoxia survival in human breast cancer cell lines. Cancer Res 2000;60:7106-13.

21. Dales JP, Garcia S, Meunier-Carpentier S, et al. Overexpression of hypoxia-inducible factor HIF-1 $\alpha$ predicts early relapse in breast cancer: retrospective study in a series of 745 patients. Int $J$ Cancer 2005;116:734-9.

22. Umemura S, Kurosumi M, Moriya $\mathrm{T}$, et al. Immunohistochemical evaluation for hormone receptors in breast cancer: a practically useful evaluation system and handling protocol. Breast Cancer 2006;13:232-5.

23. Egner JR. AJCC cancer staging manual. JAMA 2010;304:1726-27, New York: Springer.

24. Menéndez ST, Villaronga MÁ, Rodrigo JP, et al. Frequent aberrant expression of the human ether à go-go (hEAG1) potassium channel in head and neck cancer: pathobiological mechanisms and clinical implications. J Mol Med 2012;90:1173-84.

25. Ding XW, Yan JJ, An P, et al. Aberrant expression of ether a go-go potassium channel in colorectal cancer patients and cell lines. World J Gastroenterol 2007;13:1257.

26. Ding XW, Wang XG, Luo HS, et al. Expression and prognostic roles of Eag1 in resected esophageal squamous cell carcinomas. Dig Dis Sci 2008;53:2039-44.

27. Napp J, Monje F, Stühmer W, et al. Glycosylation of Eag1 (Kv10. 1) potassium channels. J Biol Chem 2005;280:29506-12.

28. Harris AL. Hypoxia-a key regulatory factor in tumour growth. Nat Rev Cancer 2002;2:38-47.

29. Birner $\mathrm{P}$, Schindl M, Obermair A, et al. Overexpression of hypoxia-inducible factor $1 \alpha$ is a marker for an unfavorable prognosis in early-stage invasive cervical cancer. Cancer Res 2000;60:4693-6.

30. Kurokawa T, Miyamoto M, Kato K, et al. Overexpression of hypoxia-inducible-factor $1 \alpha$ (HIF-1 $\alpha$ ) in oesophageal squamous cell carcinoma correlates with lymph node metastasis and pathologic stage. Br J Cancer 2003;89:1042-7.

31. Aebersold DM, Burri P, Beer KT, et al. Expression of hypoxia-inducible factor- $1 \alpha$ : a novel predictive and prognostic parameter in the radiotherapy of oropharyngeal cancer. Cancer Res 2001;61:2911-16.

32. Volm M, Koomägi R. Hypoxia-inducible factor (HIF-1) and its relationship to apoptosis and proliferation in lung cancer. Anticancer Res 1999;20:1527-33.

33. Kimbro K, Simons J. Hypoxia-inducible factor-1 in human breast and prostate cancer. Endocr Relat Cancer 2006;13:739-49.

34. Adams J, Carder PJ, Downey S, et al. Vascular endothelial growth factor (VEGF) in breast cancer: comparison of plasma, serum, and tissue VEGF and microvessel density and effects of tamoxifen. Cancer Res 2000;60:2898-905.

35. Hanahan D, Christofori G, Naik P, et al. Transgenic mouse models of tumour angiogenesis: the angiogenic switch, its molecular controls, and prospects for preclinical therapeutic models. Eur J Cancer 1996;32:2386-93.

36. Skobe M, Rockwell P, Goldstein N, et al. Halting angiogenesis suppresses carcinoma cell invasion. Nat Med 1997;3:1222-7.

37. Gruber G, Greiner RH, Hlushchuk R, et al. Hypoxia-inducible factor 1 alpha in high-risk breast cancer: an independent prognostic parameter. Breast Cancer Res 2004:6:R191-8.

38. de Queiroz FM, Suarez-Kurtz G, Stühmer W, et al. Ether a go-go potassium channel expression in soft tissue sarcoma patients. $\mathrm{Mol}$ Cancer 2006;5:42

39. Gómez-Varela D, Kohl T, Schmidt M, et al. Characterization of Eag1 channel lateral mobility in rat hippocampal cultures by single-particle-tracking with quantum dots. PLOS ONE 2010;5:e8858.

40. Chen $Y$, Sánchez A, Rubio ME, et al. Functional Kv10.1 channels localize to the inner nuclear membrane. PLoS ONE 2011;6:e19257.

41. Kallio PJ, Okamoto K, O'Brien S, et al. Signal transduction in hypoxic cells: inducible nuclear translocation and recruitment of the CBP/p300 coactivator by the hypoxia-inducible factor-1alpha. EMBO $J$ 1998;17:6573-86

42. Treins $\mathrm{C}$, Giorgetti-Peraldi S, Murdaca J, et al. Regulation of hypoxia-inducible factor (HIF)-1 activity and expression of HIF hydroxylases in response to insulin-like growth factor I. Mol Endocrinol 2005;19:1304-17. 